\title{
Avaliação de genótipos de soja em relação ao nematoide de cisto
}

\author{
Éder Matsuo ( $\left.{ }^{1 *}\right)$; Tuneo Sediyama ( $\left.{ }^{(}\right)$; Rosângela D’Arc de Lima Oliveira ( ${ }^{2}$ ); \\ Cosme Damião Cruz ( $\left.{ }^{3}\right)$; Rita de Cássia Teixeira Oliveira ( ${ }^{4}$ ) \\ (') Universidade Federal de Viçosa (UFV), Departamento de Fitotecnia, 36570-000 Viçosa (MG), Brasil. \\ (2) UFV, Departamento de Fitopatologia, 36570-000 Viçosa (MG), Brasil. \\ (3) UFV, Departamento de Biologia Geral, 36570-000 Viçosa (MG), Brasil. \\ (4) Bacuri Pesquisa e Melhoramento, Rua Aimorés, 290, 36570-000 Viçosa (MG), Brasil. \\ (*) Autor correspondente: matsuoeder@yahoo.com.br
}

Recebido: 25/out./2011; Aceito: 27/fev./2012

\begin{abstract}
Resumo
Heterodera glycines é um fitonematoide de importância econômica para a cultura da soja. Por isso, objetivou-se comparar metodologias para a avaliação de genótipos de soja em relação a este nematoide. Foram desenvolvidos dois experimentos (Ensaios A e B), em casa de vegetação, em delineamento inteiramente casualizado com seis repetições. No ensaio A, utilizaram-se vasos de cerâmica de 0,8 dm $^{3}$ e métodos-padrão de inoculação e avaliação. No ensaio B, utilizaram-se vasos de polietileno de $0,5 \mathrm{dm}^{3}$ preenchidos com solo infestado e análise visual. Foram avaliados genótipos promissores de diferentes programas de melhoramento genético de soja. Dos genótipos analisados, em 74\% havia número de fêmeas semelhantes em ambos os ensaios. O coeficiente de correlação entre o número de fêmeas do Ensaio $A$ e o número de fêmeas do Ensaio B foi de 0,85 ( $p<0,01$ ) e entre o número de fêmeas do Ensaio $A$ e a nota visual do número de fêmeas Ensaio $B$ foi 0,90 ( $p<0,01$ ). Os métodos-padrão de inoculação e avaliação utilizando solo infestado e análise visual foram, de maneira geral, coerentes entre si. Foram identificados genótipos resistentes (UFVS 2010 e BCR1070G229) e moderadamente resistentes (BCR132390, BCR945G114 e BCR1057G163) ao nematoide de cisto raça 3, pelos dois métodos de avaliação.
\end{abstract}

Palavras-chave: Glycine max, Heterodera glycines, melhoramento de soja, cultivares resistentes.

\section{Evaluation of soybean genotypes in relation to the cyst nematode}

\section{Abstract}

Heterodera glycines is a phytonematode of economic importance in the soybean crop. Therefore, the objective was to compare methodologies for evaluation of soybean genotypes in relation to $\mathrm{H}$. glycines. Two experiments were conducted (trials $A$ and $B$ ) under greenhouse condition in a completely randomized design with six replications. In the trial A, ceramic pots of $0.8 \mathrm{dm}^{3}$ and standard methodologies of inoculation and assessment were used. In the trial B, polyethylene pots filled with $0.5 \mathrm{dm}^{3}$ infested soil and visual analysis were used. Promising genotypes obtained by different soybean genetic breeding programs were evaluated. Seventy four percent of the studied genotypes presented similar numbers of females in both trials. The correlation coefficient between the number of female in trial $A$ and the number of female in trial $B$ was 0.85 ( $p<0.01$ ) and between the number of female in trial $A$ and the visual rating of the number of females in trial $B$ was $0.90(p<0.01)$. The standard methodologies of inoculation and evaluation using infested soil and visual analysis were, in general, mutually consistent. Genotypes identified as resistant (UFVS 2010 and BCR1070G229) and moderately resistant (BCR132390, BCR945G114 and BCR1057G163) to the cyst nematode race 3 were found by the two methods of assessment.

Key words: Glycine max, Heterodera glycines, soybean breeding, resistant cultivars. 


\section{INTRODUÇÃO}

O nematoide de cisto (Heterodera glycines Ichinohe) é considerado um dos principais fitonematoides da cultura soja [Glycine max (L.) Merr.] (EMbrapa, 2010; Dhingra et al., 2009). Foi identificado no Brasil, pela primeira vez, na safra 1991/1992 (Lima et al. 1992; Lordello et al., 1992; Monteiro e Morais, 1992) e atualmente, está presente em dez Estados (Minas Gerais, Mato Grosso, Mato Grosso do Sul, Goiás, São Paulo, Paraná, Rio Grande do Sul, Bahia, Tocantins e Maranhão), em área estimada superior a 2,0 milhões de hectares (EMBrapa, 2010). As perdas de produtividade de grãos podem alcançar $90 \%$, dependendo do grau de infestação, suscetibilidade da cultivar, fertilidade do solo e raça do nematoide (DHINGra et al., 2009). Assim, no agronegócio brasileiro (24 milhôes de hectares plantados e produção estimada de 70,3 milhóes de toneladas, na safra 2010/2011 - CONAB, 2011) pode ocorrer, nas próximas safras, interferência em função da ocorrência deste fitonematoide.

Os sintomas aparecem em reboleira e as plantas atacadas pelo nematoide têm seu crescimento reduzido, folhas cloróticas, diminuição da taxa fotossintética, baixa produtividade, podendo ocorrer morte prematura das plantas (Riggs e Schmitt, 1993; Freitas et al., 2004; Asmus e Ferraz, 2005). Entretanto, o diagnóstico definitivo deve ser realizado com base na presença de fêmeas de cor branca ou amarela presas às raízes (Mendes, 1993).

Em áreas onde o problema já foi identificado, o nematoide de cisto da soja (NCS) pode ser controlado utilizando-se de estratégias que incluem o uso de cultivares resistentes e o manejo integrado da soja, sendo recomendada a combinação das estratégias disponíveis (EMBRAPA, 2010). O mecanismo de resistência é do tipo "reação de hipersensibilidade", isto é, os tecidos afetados morrem e o nematoide não consegue completar seu desenvolvimento (Schmitt e Noel, 1984). Com base em um levantamento preliminar, realizado em áreas infestadas com NCS para avaliação da resistência das plantas, Mendes e Machado (1992) afirmaram que as principais cultivares de soja recomendadas para o Brasil foram suscetíveis. Por esse motivo, a estratégia mais utilizada em programas de melhoramento para a incorporação de resistência ao NCS tem sido a seleção de linhagens, a partir de populaçôes originadas de hibridaçóes entre genótipos adaptados e cultivares norte-americanas resistentes e, à medida que cultivares resistentes foram disponibilizadas no País, passaram a substituir, com vantagens, as fontes de resistência norte-americanas (DiAs et al., 2009). Na Embrapa Soja, para aumentar a frequência de linhagens resistentes ao NCS, quando possível, estas são avaliadas com base em notas, de acordo com o número de fêmeas nas raízes, em campo ou em saco de polietileno contendo solo infestado e, para garantir a pureza genética das sementes da nova cultivar, com relação à resistência ao NCS (DiAs et al., 2009). Experimentos semelhantes têm sido desenvolvidos em casa de vegetação (Valle et al., 1996; Rocha et al., 2000) ou em campo (Koenning et al., 1992; Bruin e Pedersen, 2008).

Diante do exposto, este trabalho teve como objetivo comparar metodologias para a avaliação de genótipos de soja em relação ao nematoide de cisto.

\section{MATERIAL E MÉTODOS}

\section{Informações gerais}

Foram desenvolvidos dois experimentos, em condiçōes de casa de vegetação $\left(20^{\circ} 45^{\prime} 14\right.$ ” S; 4252'54”W; 649 m de altitude), no ano agrícola 2008/2009. Em cada um, foram avaliados 27 genótipos de soja (Tabela 1) em delineamento inteiramente casualizado com seis repetiçôes, sendo cada unidade experimental representada por uma planta, cultivada em um vaso. $\mathrm{O}$ material genético foi constituído de genótipos promissores de diferentes programas de melhoramento genético de soja, tendo a cultivar UFVS 2010 como padrão de resistência e as cultivares Emgopa 313 e Lee 74 como padrôes de suscetibilidade. Os genótipos avaliados originaram de hibridaçôes realizadas contendo pelo menos um genitor com resistência ao NCS raça 3 e estavam na geração $\mathrm{F}_{8}$.

No ensaio A (Ens.A), utilizaram-se vasos de cerâmica, contendo $0,8 \mathrm{dm}^{3}$ de uma mistura de solo argiloso e areia $(1: 1)(\mathrm{v} / \mathrm{v})$, sem nematoide de cisto, segundo os métodos-padrão de inoculação ( 4.000 ovos planta $^{-1}$ ) e avaliação com base em Schmitt e Shannon (1992) e Oostenbrink (1966). No ensaio B (Ens.B) utilizaram-se vasos de polietileno de $0,5 \mathrm{dm}^{3}$ preenchidos com solo infestados, procedendo-se análise visual.

O NCS foi proveniente do Banco de Nematoides do Programa Melhoramento Genético de Soja da Universidade Federal de Viçosa (BNPMGS-UFV), que contem diversas raças de $H$. glycines provenientes de diferentes regiōes do Brasil.

\section{Obtenção do inóculo e inoculação}

Dentre as diferentes raças presentes no BNPMGS-UFV, foram utilizadas, neste trabalho, aquelas previamente caracterizadas como raça 3 por Silva et al. (1999). Portanto, coletou-se amostra de $3 \mathrm{dm}^{3}$ de 10 populaçôes caracterizadas como raça 3. Posteriormente, procedeu-se a homogeneização do solo das amostras e a semeadura da cultivar de soja Quartzo, visando à multiplicação e manutenção da população do nematoide, para a obtenção do inóculo (ovos), para o Ensaio A, e solo infestado, para o Ensaio B. Aos 41 dias após a semeadura, o sistema radicular das plantas foi removido do solo, colocado sobre uma peneira de 20 mesh acoplada a uma de 100 mesh e lavado sob jato 


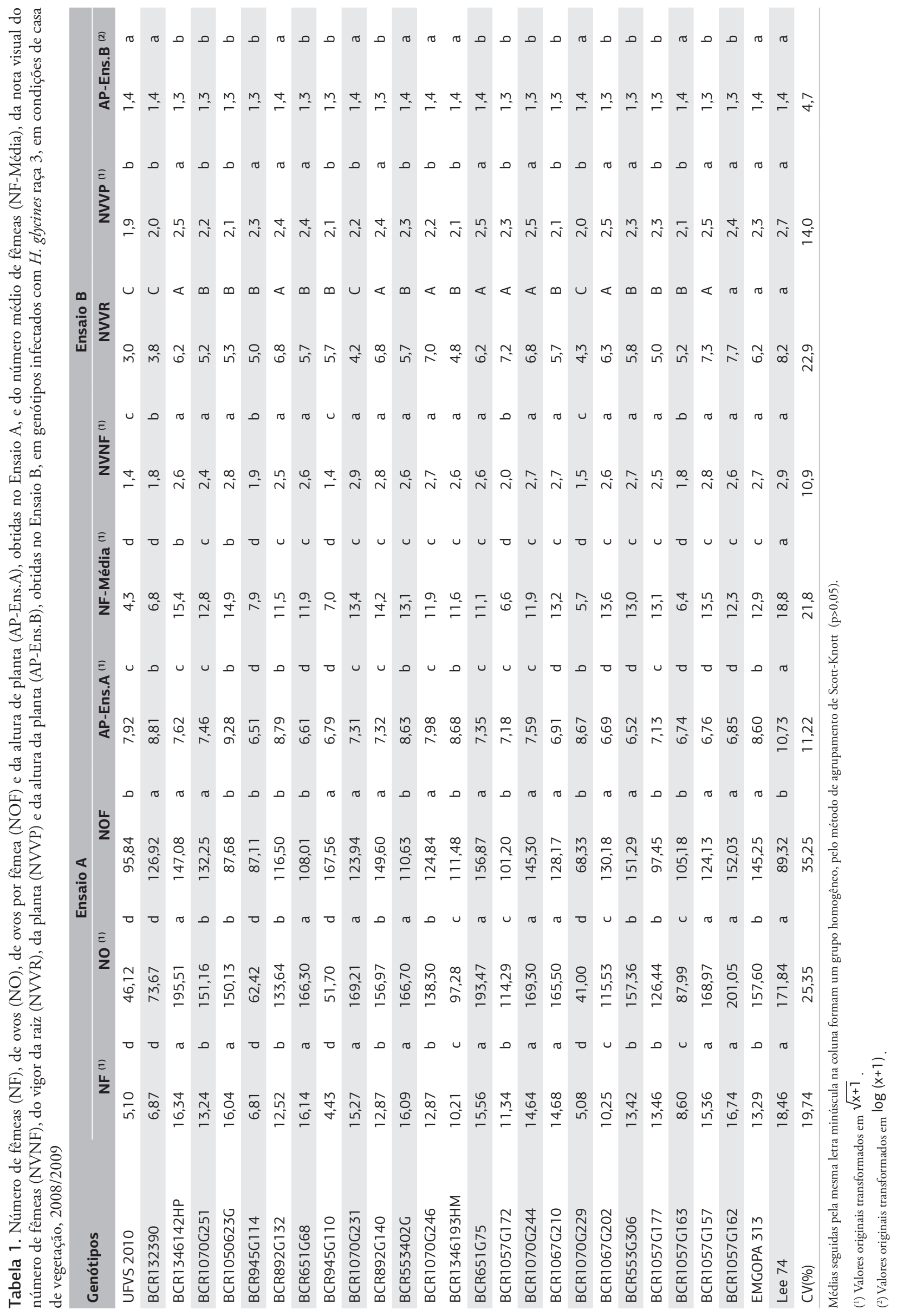


forte de água. O conteúdo da peneira de 100 mesh foi recolhido em béquer e transferido para peneira de 100 mesh acoplada a uma de 500 mesh para ser esmagado, com auxílio de um tubo de ensaio. $\mathrm{O}$ material retido nesta última peneira, principalmente os ovos, foi recolhido em outro béquer. Estimou-se a concentração da suspensão, em câmara de Peters com auxílio do microscópio de luz (aumento de 200x), para padronizá-la em 1.000 ovos $\mathrm{mL}^{-1}$.

No ensaio $A$, os vasos de cerâmicas foram preenchidos com solo sem NCS e as sementes dos 27 genótipos germinadas em leito de areia, visando à padronização das plântulas (altura e vigor) para transplantio. Para a inoculação, foram feitos quatro orifícios com $2 \mathrm{~cm}$ de profundidade no solo sem NCS, distantes $2 \mathrm{~cm}$ da haste principal, com bastão de vidro de $8 \mathrm{~mm}$ de diâmetro. Foram distribuídos 1.000 ovos em cada orifício, totalizando 4.000 ovos planta ${ }^{-1}$. O experimento foi desenvolvido de acordo com as recomendaçóes da cultura.

No ensaio B, os vasos foram preenchidos com o solo infestado com NCS. Posteriormente, plântulas em VC, segundo Fehr e Caviness (1977), de 27 genótipos de soja foram transplantadas uma por vaso. Após o transplantio, o experimento foi desenvolvido de acordo com as recomendaçôes da cultura. Neste ensaio, pelo fato de ter sido utilizado solo infestado foi necessário verificar se o número de cisto, de fêmeas e de ovos era igual entre as repetiçóes do experimento. Para isto, procederam-se a coleta e análise de três amostras de solo, de cada repetiçáo, pela método proposto por DUNN (1969) e o resultado foi submetido ao teste $\mathrm{F}$.

\section{Caracteres avaliados}

No ensaio A, o sistema radicular foi cuidadosamente removido do solo aos 34 dias após a inoculação, e individualmente lavado sob jato forte de água, em peneira de 20 mesh acoplada a outra de 160 mesh. As fêmeas retidas na peneira de 160 mesh foram recolhidas, com água, em um béquer. Posteriormente, foram contadas sob microscópio estereoscópico (aumento de 20x) com auxílio de uma placa de contagem de plástico com fundo quadriculado. Com base no número de fêmeas foi estimado o índice de fêmeas (IF), obtido pela razão entre o número de fêmeas no genótipo e o padrão de suscetibilidade (Lee 74), multiplicado por 100. Além do número de fêmeas, foram avaliados o número de ovos, número de ovos por fêmeas, fator de reprodução (Oostenbrink, 1966) e alguns caracteres agronômicos como: altura de plantas $(\mathrm{AP})(\mathrm{cm})$, número de nós $(\mathrm{NN})$, matéria verde da parte aérea (PMV) (g) e matéria seca da parte aérea (PMS) (g). O comportamento dos genótipos quanto ao NCS foi avaliado segundo Schmitt e SHAnNon (1992) e Oostenbrink (1966).

No ensaio B, aos 35 dias após o transplante das plântulas no solo infestado, o sistema radicular de cada planta foi cuidadosamente removido do solo, lavado e colocado sobre jornal. Avaliou-se o número de fêmeas com base em escala de notas visuais (NVNF) (1: de 0 a $9 \%$ do sistema radicular com presença de fêmeas; 2 : de $10 \%$ a $19 \%$ do sistema radicular com presença de fêmeas; 3: de 20\% a 29\% do sistema radicular com presença de fêmeas; 4 : de 30\% a 39\% do sistema radicular com presença de fêmeas; 5: de $40 \%$ a $49 \%$ do sistema radicular com presença de fêmeas; 6: de 50\% a $59 \%$ do sistema radicular com presença de fêmeas; 7: de $60 \%$ a $69 \%$ do sistema radicular com presença de fêmeas; 8: de $70 \%$ a $79 \%$ do sistema radicular com presença de fêmeas; 9: de $80 \%$ a $89 \%$ do sistema radicular com presença de fêmeas; e 10: de $90 \%$ a $100 \%$ do sistema radicular com presença de fêmeas), nota visual do vigor da raiz (NVVR) e da planta (NVVP) (valores variando de 1 (maior vigor) a 10 (menor vigor), comparando o genótipo em teste com a cultivar Lee 74). Posteriormente, contou-se o número de fêmeas com auxílio de uma lupa de mão (aumento de 6x) e um filme de polietileno preto. $\mathrm{O}$ número de fêmeas foi contado por três avaliadores, no entanto, utilizou-se a média dos avaliadores nas análises (NF-Média). Além disso, mensuraram-se os caracteres agronômicos avaliados no ensaio A. O comportamento dos genótipos quando ao $H$. $g l y$ cines foi avaliado segundo Schmitt e SHAnnon (1992).

\section{Análises estatísticas}

Os dados, quando necessários, foram transformados antes de se proceder a análise de variância. Inicialmente, separadamente para cada ensaio, realizou-se a análise de variância e o agrupamento das médias dos genótipos, para cada caráter, pelo teste de Scott-Knott ( $\mathrm{p}=0,05)$.

Posteriormente, para cada genótipo, compararam-se o número de fêmeas obtido nos ensaios $\mathrm{A}$ e $\mathrm{B}$ pelo teste $\mathrm{t}$ $(\mathrm{p} \leq 0,05)$. Estimaram-se, também, o coeficiente de correlação de Pearson entre os caracteres mensurados, os quais foram testados pelo teste $t(\mathrm{p} \leq 0,05$ e $\mathrm{p} \leq 0,01)$, e o coeficiente de coincidência, considerando o tamanho da amostra igual a 6 (20\%). Segundo Cruz (2001) no coeficiente de coincidência, calcula-se a concordância de ocorrência de genótipos no conjunto formado pelas observaçôes superiores ou inferiores, para cada par de caracteres, em relação a uma amostra de tamanho $n_{1}$, de forma que $n_{1}$ seja menor que $n$ (onde $n=$ número total de genótipos). As análises estatísticas foram realizadas no Programa Genes: Programa Computacional em Genética e Estatística (CruZ, 2001).

\section{RESULTADOS}

\section{Ensaio A}

Verificaram-se diferenças significativas $(\mathrm{p}<0,05)$ entre os genótipos para número de fêmeas, de ovos, de 
ovos por fêmea e altura de planta (AP-Ens.A). Os genótipos BCR132390, BCR945G114, BCR945G110, BCR1070G229 e UFVS 2010 formaram um grupo homogêneo para número de fêmeas e de ovos, que diferiu significativamente dos grupos que agruparam as cultivares Lee 74 e a Emgopa 313, que são padrões de suscetibilidade. Analisando a AP-Ens.A verificou-se que UFVS 2010, EMGOPA 313 e Lee 74 foram classificados em grupos distintos, sendo 37,5\% agrupados com UFVS 2010, 25,0\% com EMGOPA 313, 37,5\% em grupo homogêneo e diferente estatisticamente e a Lee 74 formou um grupo exclusivo (Tabela 1).

\section{Ensaio B}

O número de cisto, de fêmeas e de ovos, entre as repetições do ensaio $\mathrm{B}$, proporcionaram médias não significativas $(p>0,05)$ pelo teste $F$, demonstrando que o solo infestado foi bem homogeneizado antes de preencher os vasos. A população inicial do solo infestado utilizado foi de 205,5 fêmeas e cisto e 28.211,67 ovos por $100 \mathrm{dm}^{3} \mathrm{de}$ solo. Ressalta-se a necessidade de misturar bem o solo infestado e determinar sua infestação, posto que, provavelmente, os resultados da avaliaçáo de genótipos de soja em relação ao nematoide de cisto com solo infestado dependem da sua infestaçáo.

Observaram-se diferenças significativas $(\mathrm{p}<0,05)$ entre genótipos nos caracteres: NF-Média, NVNF, NVVR, NVVP e AP-Ens.B. Analisando o grupo com as menores médias do NF-Média, verificou-se que os genótipos BCR132390, BCR945G114, BCR945G110, BCR1057G172, BCR1070G229, BCR1057G163 e UFVS 2010 formaram um grupo homogêneo, enquanto o genótipo Lee 74 constituiu-se em um grupo exclusivo com a maior média (Tabela 1 ).

Com base na escala de NVNF e NVVR observou-se formação de três grupos homogêneos, enquanto NVVP e AP-Ens.B tinham apenas dois grupos. Baseando-se em NVVR, os genótipos BCR132390, BCR1070G231, BCR1070G229 e UFVS 2010 foram alocados no grupo de menor média, enquanto para NVNF agruparam-se os genótipos BCR945G110, BCR1070G229 e UFVS 2010 (Tabela 1).

\section{Comparação entre os ensaios}

Dos 27 genótipos avaliados, incluindo os padrôes de resistência e suscetibilidade, $74 \%$, isto é, em 20 genótipos as médias do número de fêmeas foram semelhantes $(p>0,05)$ entre os ensaios, pelo teste t. Ao analisar as médias dos genótipos com diferenças, observou-se maior média nos genótipos BCR651G68, BCR553402G, BCR651G75, BCR1057G172 e BCR1057G162 no ensaio $A$, enquanto no ensaio $B$, as maiores médias foram anotadas em BCR945G110 e BCR1070G229 (Tabela 2).

Verificou-se coeficiente de correlação maior que 0,85 $(\mathrm{p}<0,01)$ entre o número de fêmeas avaliado nos ensaios $\mathrm{A}$ e $\mathrm{B}$. O coeficiente de correlação entre número de fêmeas (Ensaio $\mathrm{A}$ ) com a nota visual do número de fêmeas (Ensaio $B)$ foi de $0,90(p<0,01)$. As correçóes do número de fêmeas (Ensaio A) com a nota visual do vigor da raiz e do vigor da plantas foram, respectivamente, iguais a 0,58 $(\mathrm{p}<0,01)$ e $0,64(\mathrm{p}<0,01)$ (Tabela 3$)$.

Os resultados dos coeficientes de coincidência entre os 6 genótipos com médias inferiores, isto é, $20 \%$ dos genótipos analisados, demonstraram que os valores entre os caracteres número de fêmeas e de ovos, do ensaio $\mathrm{A}$, com os números de fêmeas e notas visuais, do ensaio $\mathrm{B}$, variaram de $60 \%$ a $80 \%$. Os coeficientes de coincidência entre NF-Média e NVNF, no ensaio B, foi de $80 \%$. Os coeficientes de correlação e de coincidência entre número de fêmeas e de ovos do ensaio A foram, respectivamente, iguais a $0,95(\mathrm{p}<0,01)$ e de $100 \%$ (Tabela 3 ).

No caráter altura de planta, observou-se magnitude de $-0,35$ a 0,24 com p $>0,05$ em $85 \%$ dos coeficientes de

Tabela 2. Número(1) de fêmeas em genótipos de soja nos ensaios (A e B), em condiçốes de casa de vegetação, 2008/2009

\begin{tabular}{|c|c|c|c|c|}
\hline Genótipos & Ensaio A & & Ensaio B & \\
\hline UFVS 2010 & 5,10 & A & 4,26 & A \\
\hline BCR132390 & 6,87 & A & 6,77 & A \\
\hline BCR1346142HP & 16,34 & A & 15,42 & A \\
\hline BCR1070G251 & 13,24 & A & 12,79 & A \\
\hline BCR1050623G & 16,04 & A & 14,88 & A \\
\hline BCR945G114 & 6,81 & A & 7,86 & A \\
\hline BCR892G132 & 12,52 & A & 11,53 & A \\
\hline BCR651G68 & 16,14 & A & 11,94 & B \\
\hline BCR945G110 & 4,43 & B & 6,98 & A \\
\hline BCR1070G231 & 15,27 & A & 13,43 & A \\
\hline BCR892G140 & 12,87 & A & 14,24 & A \\
\hline BCR553402G & 16,09 & A & 13,10 & B \\
\hline BCR1070G246 & 12,87 & A & 11,92 & A \\
\hline BCR1346193HM & 10,21 & A & 11,61 & A \\
\hline BCR651G75 & 15,56 & A & 11,09 & B \\
\hline BCR1057G172 & 11,34 & A & 6,64 & B \\
\hline BCR1070G244 & 14,64 & A & 11,92 & A \\
\hline BCR1067G210 & 14,68 & A & 13,18 & A \\
\hline BCR1070G229 & 5,08 & $\mathrm{~B}$ & 5,68 & A \\
\hline BCR1067G202 & 10,25 & A & 13,58 & A \\
\hline BCR553G306 & 13,42 & A & 13,02 & A \\
\hline BCR1057G177 & 13,46 & A & 13,08 & A \\
\hline BCR1057G163 & 8,60 & A & 6,38 & A \\
\hline BCR1057G157 & 15,36 & A & 13,47 & A \\
\hline BCR1057G162 & 16,74 & A & 12,26 & B \\
\hline EMGOPA 313 & 13,29 & A & 12,85 & A \\
\hline Lee 74 & 18,46 & A & 18,84 & A \\
\hline
\end{tabular}

Médias seguidas pela mesma letra maiúscula na linha năo diferem entre si pelo teste $\mathrm{t}(\mathrm{p}>0,05)$.

(1) Valores originais transformados em $\sqrt{\mathrm{x}+1}$. 
Tabela 3. Coeficientes de correlação de Pearson (acima da diagonal) e coeficientes de coincidência, em \%, referente às médias inferiores (abaixo da diagonal) entre nove caracteres avaliados em genótipos de soja, infectados com nematoide de cisto (Heterodera glycines) raça 3 , em condiçóes de casa de vegetação, 2008/2009

\begin{tabular}{|c|c|c|c|c|c|c|c|c|c|c|}
\hline \multirow{2}{*}{\multicolumn{2}{|c|}{ Caracteres }} & \multicolumn{4}{|c|}{ Ensaio A } & \multicolumn{5}{|c|}{ Ensaio B } \\
\hline & & NF & NO & NOF & AP-Ens.A & NF-Média & NVNF & NVVR & NVVP & AP-Ens.B \\
\hline \multirow{4}{*}{ 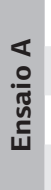 } & $\mathrm{NF}$ & - & $0,9594^{* *}$ & 0,2021 & 0,1360 & $0,8531^{* *}$ & $0,9006^{* *}$ & $0,5875^{* *}$ & $0,6440^{* *}$ & $-0,0240$ \\
\hline & NO & 100 & - & $0,4363^{*}$ & $-0,0125$ & $0,8023^{* *}$ & $0,8803^{* *}$ & $0,6008^{* *}$ & $0,6559^{* *}$ & $-0,0800$ \\
\hline & NOF & 60 & 60 & - & $-0,3823^{*}$ & 0,2142 & 0,2691 & 0,3160 & 0,2724 & $-0,2683$ \\
\hline & AP-Ens.A & 20 & 20 & 20 & - & 0,2429 & 0,1041 & 0,0357 & 0,0037 & $0,5816^{* *}$ \\
\hline \multirow{5}{*}{ 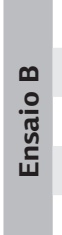 } & NF-Média & 60 & 60 & 40 & 20 & - & $0,9156^{* *}$ & $0,5457^{* *}$ & $0,6893^{* *}$ & $-0,0927$ \\
\hline & NVNF & 80 & 80 & 40 & 20 & 80 & - & $0,5641^{* *}$ & $0,6446^{* *}$ & $-0,0385$ \\
\hline & NVVR & 60 & 60 & 40 & 0 & 60 & 60 & - & $0,7754^{* *}$ & $-0,3068$ \\
\hline & NVVP & 80 & 80 & 60 & 0 & 60 & 80 & 60 & - & $-0,3507$ \\
\hline & AP-Ens.B & 40 & 40 & 20 & 40 & 20 & 20 & 0 & 20 & - \\
\hline
\end{tabular}

*, **: significativo com $\mathrm{p} \leq 0,05$ e $\mathrm{p} \geq 0,01$, respectivamente, pelo teste $\mathrm{t}$.

Ensaio A: NF (número de fêmeas), NO (número de ovos), NOF (número de ovos por fêmeas) e AP-Ens.A (altura de plantas);

Ensaio B: NF-Média (número de fêmeas obtido pela média dos três avaliadores), NVNF (nota visual do número de fêmeas), NVVR (nota visual do vigor da raiz), NVVP (nota visual do vigor da planta) e AP-Ens.B (altura de plantas).

correlação obtidos. Os coeficientes de coincidência variaram de 0 a $40 \%$ para com todos os caracteres avaliados (Tabela 3).

No ensaio A, os genótipos BCR945G110, BCR1070G229 e UFVS 2010 comportaram-se como resistentes ao nematoide de cisto, raça 3 , enquanto, BCR132390, BCR945G114 e BCR1057G163 foram classificados como moderadamente resistentes pelo índice de fêmea e suscetíveis pelo fator de reprodução. No ensaio B, os genótipos UFVS 2010 e BCR1070G229 comportaram-se como resistentes e BCR132390, BCR945G114, BCR945G110, BCR1057G172 e BCR1057G163 com comportamento de moderada resistência. Os demais se comportaram como moderadamente suscetíveis ou suscetíveis quando submetidos ao NCS, tanto no ensaio A quanto no B (Tabela 4).

A avaliação de cada sistema radicular necessitou de 25 minutos para a extração e contagem das fêmeas e de 25 minutos para a extraçáo e contagem do número de ovos, no ensaio A. No ensaio B, necessitou-se de 1,67 minutos (100 segundos) para avaliação do sistema radicular com base na escala de notas visuais do número de fêmeas e de 15 minutos para contagem do número de fêmeas diretamente no sistema radicular com lupa.

\section{DISCUSSÃO}

A formação de diferentes grupos de genótipos para os caracteres avaliados ocorreu devido à existência de variabilidade genética entre os materiais analisados, mesmo porque, alguns genótipos possuem genes de resistência e outros não, apesar de serem descendentes de genitores resistentes ao NCS. Segundo Schmitt e Noel (1984), o mecanismo de resistência é do tipo "reação de hipersensibilidade", isto é, os tecidos afetados morrem e o nematoide não consegue completar seu desenvolvimento. Desta forma, os grupos com certa resistência genética ao NCS foram formados pelas menores médias de número de fêmeas, de ovos e notas visuais e pelo padrão de resistência.

As variaçôes observadas entre os ensaios podem ter ocorrido pelo fato de as fêmeas serem muito pequenas ou estarem se transformando em cisto. Assim, sua visualização torna-se reduzida, mesmo com a utilização de lupa de aumento. As fêmeas têm corpo no formato de limão com comprimento variando de $150 \mu \mathrm{m}$ a $790 \mu \mathrm{m}$ e a largura de $152 \mu \mathrm{m}$ a $268 \mu \mathrm{m}$, coloração inicial branca perolada, mas quando próximas de se desprenderem da raiz, sua tonalidade se torna amarronzada (Turner e Rowe, 2006).

A correlação reflete o grau de associaçấo entre os caracteres e é importante seu conhecimento porque mostra como a seleção para um caráter influncia a expressão de outro (Cruz et al., 2004). A classificação da resistência da soja ao NCS foi realizada segundo Schmitt e SHANnon (1992) e Oostenbrink (1966), então, as correlaçóes positivas, de alta magnitude e significativas foram consideradas as de maior importância, no que se refere a número de fêmeas, de ovos e notas visuais. Consideraram-se estimativas de alta magnitude os valores acima de 0,70 $(\mathrm{p}<0,01)$ pelo fato de que, ao elevar ao quadrado e considerar a relaçáo linear entre as características, o coeficiente de determinação resultante seria igual a $49 \%$, isto é, $49 \%$ da variação de um caráter são explicados pela variação em outro. Segundo Cruz et al. (2004), coeficientes de correlação fenotípicos não significativos $(\mathrm{p}>0,05)$ não implica falta de relação entre duas variáveis, apenas refletem a ausência da relação linear entre os caracteres estudados.

$\mathrm{O}$ uso de solo infestado com NCS e a análise visual foram eficientes na classificação dos genótipos em 
Tabela 4. Comportamento de 27 genótipos de soja, com base no índice de fêmeas (IF) e fator de reprodução (FR) no ensaio A e índice de fêmeas (IF) no ensaio B, infectados com H. glycines, raça 3, em condiçóes de casa de vegetação, 2008/2009 ${ }^{(1)}$

\begin{tabular}{|c|c|c|c|c|c|c|}
\hline \multirow{3}{*}{$\begin{array}{l}\text { Genótipos } \\
\text { UFVS } 2010\end{array}$} & \multicolumn{4}{|c|}{ Ensaio A } & \multirow{2}{*}{\multicolumn{2}{|c|}{$\begin{array}{c}\text { Ensaio B } \\
\text { IF }\end{array}$}} \\
\hline & \multicolumn{2}{|c|}{ IF } & \multicolumn{2}{|c|}{ FR } & & \\
\hline & 7,5 & (R) & 0,6 & $(\mathrm{R})$ & 5,0 & (R) \\
\hline BCR132390 & 13,6 & (MR) & 1,4 & (S) & 12,6 & (MR) \\
\hline BCR1346142HP & 76,8 & (S) & 9,7 & (S) & 69,3 & (S) \\
\hline BCR1070G251 & 50,3 & (MS) & 5,9 & (S) & 46,5 & (MS) \\
\hline BCR1050623G & 75,1 & (S) & 6,0 & (S) & 62,1 & (S) \\
\hline BCR945G114 & 13,3 & (MR) & 1,0 & (S) & 17,1 & (MR) \\
\hline BCR892G132 & 47,2 & (MS) & 5,4 & (S) & 40,0 & (MS) \\
\hline BCR651G68 & 75,0 & (S) & 7,0 & (S) & 41,1 & (MS) \\
\hline BCR945G110 & 6,1 & (R) & 0,8 & $(\mathrm{R})$ & 13,4 & (MR) \\
\hline BCR1070G231 & 68,4 & (S) & 7,4 & (S) & 50,4 & (MS) \\
\hline BCR892G140 & 48,0 & (MS) & 6,3 & (S) & 57,2 & (MS) \\
\hline BCR553402G & 74,4 & (S) & 7,3 & (S) & 50,6 & (MS) \\
\hline BCR1070G246 & 48,9 & (MS) & 5,0 & (S) & 40,8 & (MS) \\
\hline BCR1346193HM & 37,4 & (MS) & 2,8 & (S) & 39,0 & (MS) \\
\hline BCR651G75 & 70,4 & (S) & 9,5 & (S) & 35,7 & (MS) \\
\hline BCR1057G172 & 39,9 & (MS) & 3,7 & (S) & 12,0 & (MR) \\
\hline BCR1070G244 & 63,7 & (S) & 7,3 & (S) & 40,3 & (MS) \\
\hline BCR1067G210 & 62,4 & (S) & 7,1 & (S) & 49,3 & (MS) \\
\hline BCR1070G229 & 7,1 & $(\mathrm{R})$ & 0,4 & $(\mathrm{R})$ & 8,7 & (R) \\
\hline BCR1067G202 & 32,2 & (MS) & 3,7 & (S) & 55,0 & (MS) \\
\hline BCR553G306 & 53,0 & (MS) & 6,6 & (S) & 48,1 & (MS) \\
\hline BCR1057G177 & 52,8 & (MS) & 4,2 & (S) & 48,6 & (MS) \\
\hline BCR1057G163 & 22,9 & (MR) & 2,3 & (S) & 11,2 & (MR) \\
\hline BCR1057G157 & 68,1 & (S) & 7,2 & (S) & 50,9 & (MS) \\
\hline BCR1057G162 & 81,8 & (S) & 10,3 & (S) & 43,6 & (MS) \\
\hline EMGOPA 313 & 52,2 & (MS) & 6,4 & (S) & 49,6 & (MS) \\
\hline Lee $74^{(2)}$ & 100,0 & (S) & 8,0 & (S) & 100,0 & (S) \\
\hline
\end{tabular}

(1) O cálculo do índice de fêmeas e fator de reproduçăo foi realizado com as médias originais ( $\mathrm{n}=6$ repetiçóes);

() Número médio de fêmeas em Lee 74 no ensaio A foi de 348; e no ensaio B de 359,83.

R: resistente; MR: moderadamente resistente; MS: moderadamente suscetível; S: suscetível.

resistentes, moderadamente resistentes e suscetíveis. Portanto, pode ser considerada importante estratégia a ser utilizada na seleção preliminar em programas de melhoramento genético de soja, dada a necessidade de avaliar grande número de progênies. Assim, o número de linhagens com resistência ao $H$. glycines, a ser confirmado com solo devidamente esterilizado, infectado com ovos de NCS e posterior contagem de fêmeas e ovos em microscópios, poderá ser grandemente reduzido. Pode-se relatar como exemplo que, nas seleçôes preliminares que resultaram nas cultivares UFVS 2010, UFVS 2011 e UFVS 2012, com reação de moderada resistência a resistência ao nematoide de cisto da soja, raça 3 , foram realizadas de forma semelhante ao deste trabalho. As cultivares UFVS foram desenvolvidas pelo Programa de Melhoramento Genético de Soja da UFV. É importante ressaltar que mais estudos podem ser necessários para recomendar ou indicar o método alternativo (solo infestado e análise visual), de forma generalizada para serem utilizadas em programas de melhoramento de soja.

Salienta-se que o treinamento prévio do avaliador foi de suma importância e que a utilização de métodos-padrão de inoculação e avaliação é necessária para avaliar a presença de nematoide de cisto em sistema radicular da soja, quando o objetivo é analisar as linhagens das etapas finais de melhoramento e recomendação de cultivares. Outros trabalhos, utilizando solo infestado com NCS, em campo ou em casa de vegetação, tiveram como objetivos: aumentar a frequência de linhagens de soja, desenvolvidos pela Embrapa Soja, com resistência ao NCS (Diss et al., 2009); avaliar o ganho genético e a estabilidade de produção de cultivares de soja resistentes ao nematoide de cisto da soja (Bruin e 
Pedersen, 2008); e avaliar o efeito da aplicação do produto acibenzolar-S-methyl na induçáo de resistência sistêmica ao nematoide de cisto da soja (Rocha et al., 2000).

As escalas de notas visuais do número de fêmeas, do vigor da raiz e do vigor da planta foram eficientes na formação de grupos onde classificaram separadamente o padrão de resistência e os padrôes de suscetibilidade. Além disso, a escala de nota visual do número de fêmeas foi a mais coerente para com os números de fêmeas mensurados no ensaio A e no B. Desse modo, a avaliação foi realizada de maneira bastante simples e rápida, ao passo que no ensaio $\mathrm{A}$ foi mais demorada. O tempo necessário para analisar o comportamento dos genótipos no ensaio $\mathrm{B}$ pôde ser reduzido em aproximadamente 15 vezes quando utilizada a escala de notas visuais do número de fêmeas em relação à contagem do número de fêmeas e de ovos no ensaio A.

\section{CONCLUSÃO}

O método-padrão de inoculação e avaliação e o uso de solo infestado e análise visual foram, de maneira geral, coerentes entre si na análise do comportamento de genótipos de soja ao nematoide de cisto.

É possível identificar genótipos resistentes (UFVS 2010 e BCR1070G229) e moderadamente resistentes (BCR132390, BCR945G114 e BCR1057G163) ao nematoide de cisto raça 3 , pelos dois métodos de avaliação.

\section{AGRADECIMENTOS}

Ao Conselho Nacional de Desenvolvimento Científico e Tecnológico (CNPq-Brasil) pelo apoio financeiro na realizaçáo deste trabalho (bolsa de mestrado e de produtividade em pesquisa).

\section{REFERÊNCIAS}

ASMUS, G.L.; FERRAZ, L.C.C.B. Effect of population densities of Heterodera glycines race 3 on leaf area, photosynthesis and yield of soybean. Fitopatologia Brasileira, v.27, p.273-278, 2002.

BRUIN, J.L.; PEDERSEN, P. Yield improvement and stability for soybean cultivars with resistance to Heterodera glycines Ichinohe. Agronomy Journal, v.100, p.1354-1359, 2008.

CONAB - Companhia Nacional de Abastecimento. Disponível em: <http://www.conab.gov.br/OlalaCMS//uploads/ arquivos/11_03_10_09_03_02_boletim_marco-11[1]..pdf >. Acesso em: 2/4/2011.

CRUZ, C.D. Programa Genes: aplicativo computacional em genética e estatística. 1.ed. Viçosa: UFV, 2001. 648p.
CRUZ, C.D.; REGAZZI, A.J.; CARNEIRO, P.C.S. Modelos biométricos aplicados ao melhoramento genético. v.2. Viçosa: UFV, 2004. 480p.

DHINGRA, O.D.; MENDONÇA, H.L.; MACEDO, D.M. Doenças e seu controle. In: SEDIYAMA, T. (Ed.). Tecnologias de produção e usos da soja. 1.ed. Londrina: Mecenas, 2009. p.133155.

DIAS, W.P.; SILVA, J.F.V.; CARNEIRO, G.E.S.; GARCIA, A.; ARIAS, C.A.A. Nematoide de cisto da soja: biologia e manejo pelo uso da resistência genética. Nematologia Brasileira, v.33, p.1-16, 2009.

DUNN, R.A. Extraction of cysts of Heterodera species from soils by centrifugation in high density solution. Journal of Nematology, v.1, p.7, 1969 .

EMBRAPA - Empresa Brasileira de Pesquisa Agropecuária. Tecnologias de produção de soja - Região Central do Brasil 2011. 1.ed. Londrina: Embrapa Soja: Embrapa Cerrados: Embrapa Agropecuária Oeste, 2010. 255p.

FEHR, W.R.; CAVINESS, C.E. Stages of soybean development. Iowa, Ames, USA: Iowa State University of Science and Technology, 1977. 12p. (Special Report 80)

FREITAS, L.G.; OLIVEIRA, R.D.L.; FERRAZ, S. Introdução à nematologia. 1.ed. Viçosa: UFV, 2004, 84p.

KOENNING, S.R.; ANAND, S.C.; MYERS, G.O. An alternative method for evaluating soybean tolerance to Heterodera glycines in field plots. Journal of Nematology, v.24, p.177-182, 1992.

LIMA, R.D.; FERRAZ, S.; SANTOS, J.M. Ocorrência de Heterodera sp., em soja no Triângulo Mineiro. Nematologia Brasileira, v.16, p.101, 1992.

LORDELLO, A.I.L.; LORDELLO, R.R.A.; QUAGGIO, J.A. Ocorrência do nematoide de cisto da soja (Heterodera glycines) no Brasil. Revista de Agricultura, v.67, p.223-225, 1992.

MENDES, M.L. O nematoide do cisto da soja. In: ARANTES, N.E.; MELO DE SOUZA, P.I. (Ed.). Cultura da soja nos cerrados. Piracicaba: Potafós, 1993. p.399-416.

MENDES, M.L.; MACHADO, C.C. Levantamento preliminar da ocorrência do nematoide de cisto da soja (Heterodera glycines Ichinohe), no Brasil. Londrina: Embrapa-CNPSo, 1992. 5p.

MONTEIRO, A.R.; MORAES, S.R.A.C. Ocorrência do nematoide de cisto da soja, Heterodera glycines Ichinohe, 1952, prejudicando a cultura no Mato Grosso do Sul. Nematologia Brasileira, v.16, p.101, 1992.

OOSTENBRINK, M. Major characteristics of the relation between nematodes and plants. Mededelingen Landbouwhogeschool Wageningen, v.66, p.1-46, 1966.

RIGGS, R.D.; SCHMITT, D.P. Soybean cyst nematode. In: SINCLAIR, J.G.; BACKMAN, P.A. (Ed.). Compendium of soybean disease. USA: The American Phytopathological Society Press, 1993. p.65-67. 
ROCHA, M.R.; CASTRO, R.M.; PINA, R.C.; MARTINI, A.L. Efeito do acibenzolar-S-methyl (Benzothiadiazole), como indutor de resistência sistêmica em soja (Glycine max cv. FT-Cristalina), sobre Heterodera glycines. Pesquisa Agropecuária Tropical, v.30, p.35-38, 2000.

SCHMITT, D.P.; NOEL, G.R. Nematodes parasites of soybean. In: NICKLE, W.R. (Ed.). Plant and insect nematode. New York: Marcel Dekker, 1984. p.13-59.

SCHMITT, D.P.; SHANNON, G. Differentiating soybean responses to Heterodera glycines races. Crop Science, v.32, p.275277, 1992.
SILVA, J.A.L.; SEDIYAMA, T.; TEIXEIRA, R.C.; OLIVEIRA, R.D.L. Raças fisiológicas do nematoide de cistos da soja (Heterodera glycines), nos Estados de Goiás, Mato Grosso, Mato Grosso do Sul e Minas Gerais. Revista Ceres, v.46, p.45-52, 1999.

TURNER, S.J.; ROWE, J.A. Cyst nematodes. In: PERRY, R.N.; MOENS, M. (Ed.). Plant Nematology. UK: CAB International, 2006. p.91-122.

VALLE, L.A.C.; FERRAZ, S.; DIAS, W.P.; TEIXEIRA, D.A. Controle do nematoide de cisto da soja Heterodera glycines, com gramíneas forrageiras. Nematologia Brasileira, v.22, p.1-11, 1996. 